\title{
Smoking Model Incorporate Anti-Smoking Campaign, Nicotine Gum, and Treatment
}

\author{
Heni Widayani ${ }^{1{ }^{*}}$ Putri Lestari $^{1}$, Usman Palagay ${ }^{1}$ \\ ${ }^{1}$ Department of Mathematics, UIN Maulana Malik Ibrahim Malang, Malang, Indonesia \\ "Corresponding author.Email: heniwidayani@mat.uin-malang.ac.id
}

\begin{abstract}
The dynamics model of smoking is a system of nonlinear differential equations of first order. The dynamics model of smoking consists of five subpopulations, namely potential smokers, light smokers, heavy smokers, smokers who temporarily quit smoking, and smokers who permanently quit smoking. The mathematical model can illustrate the rate of spread of smokers. This study discusses the dynamics model of smoking by giving controls, namely anti-smoking campaign, nicotine gum, and treatment. An anti-smoking campaign is given to potential smokers, nicotine gum is given to light smokers and smokers who temporarily quit smoking and also treatment is given to heavy smokers. The solution of the optimal control on the dynamics model of smoking is derived using Pontryagin maximum principle. This principle is applied to obtain optimal conditions and also get the state and co-state equations, which are then simulated using Runge-Kutta order 4 . The numerical simulation result indicates that implementation of campaign and treatment program effectively to minimize the number of potential smoker population, light smokers, heavy smokers, and smokers who temporarily quit smoking, and to maximize the number of smokers population who permanently quit smoking.
\end{abstract}

Keywords: smoking, optimal control, anti-smoking campaign, nicotine gum, treatment.

\section{INTRODUCTION}

Nowadays, the popularity of smoking is increasingly difficult to control. Smoking is the activity of burning tobacco, then inhaling the smoke and taking it out again through the mouth. The World Health Organizations states that tobacco causes approximately 5,4 million deaths annually worldwide [7]. Smoking-related diseases include narrowing of blood vessels, high blood pressure, heart, lungs, and chronic bronchitis [4]. According to Davidson \& Neale [5] ] states that cigarette consumption in pregnant women has risks such as premature birth, weight low infant body, prenatal mortality, birth defects, and infant development disorders. Not smoking is one way to avoid these various diseases.

This has been explained by the Human Population Laboratory in the list of healthy lifestyles [6], so the prevention is needed to narrow the widespread smoking habit. These efforts can prevent an increase in the number of smokers, namely anti-smoking campaign, nicotine gum, and treatment. First, the anti-smoking campaign among young people aims to find out the dangers of smoking from an early age. Second, nicotine gum is one of the products for therapy that functions as a nicotine replacement, so that smokers can stop smoking gradually [2]. Third, the treatment method is a method of using drugs that can cure a person from dependence on cigarettes [3].

Mathematical model construction is also an effort to reduce the number of smokers. Some research about the dynamics model of smoking as follows. Alkhudari et al. [1] presented the dynamics model of smoking with the class of smokers which is divided into light smokers and heavy smokers. This research is also discussed stability analysis. Zeb et al. [9] discusses the problem of optimal control in the dynamics model of smoking with three controls namely anti-smoking campaign, nicotine gum, and treatment. The controls aim to maximize the number of smokers who permanently quit smoking. Then, Zaman [8] discusses the problem of optimal control on the dynamics model of smoking with the control of anti-smoking campaign and treatment.

In this paper, we adopt the dynamics model of smoking that developed and studied in [1]. This model consists of five subpopulations, namely potential smokers, light smokers, heavy smokers, smokers who 
temporarily quit smoking, and smokers who permanently quit smoking. We develop an optimal control strategies associated with three types of control, an anti-smoking campaign, a nicotine gum and a treatment. The anti-smoking campaign is given to potential smokers. A nicotine gum is given to light smokers and smokers who permanently quit smoking. In addition, treatment is given to heavy smokers. Our goal in this work is to maximize the number of smokers who permanently quit smoking and minimize the number of potential smokers, light smokers, heavy smokers, and smokers who temporarily quit smoking with minimal costs. We will use the Pontryagin maximum principle to determine the optimal control strategy. Numerical simulations are also given using the Runge-Kutta method of order 4 .

\section{METHODS}

In this paper, the dynamics model of smoking is a mathematical model that describe the rate of spread of smoking behavior. The following is a compartment diagram for the dynamics model of smoking in:

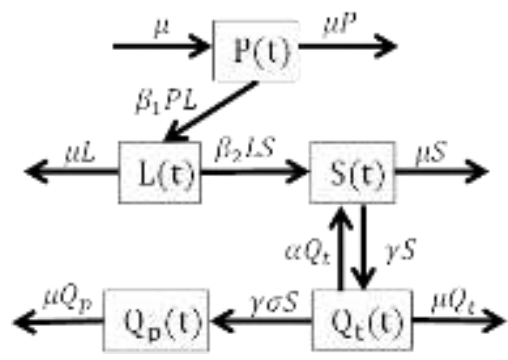

Figure 1 Compartment Diagram of Smoking Interaction

The system of differential equations presented as :

$$
\begin{aligned}
& \frac{d P(t)}{d t}=\mu-\beta_{1} P(t) L(t)-\mu P(t) \\
& \frac{d L(t)}{d t}=\beta_{1} P(t) L(t)-\beta_{2} L(t) S(t)-\mu L(t) \\
& \frac{d S(t)}{d t}=\beta_{2} L(t) S(t)+\alpha Q_{t}(t)-(\mu+\gamma) S(t) \\
& \frac{d Q_{t}(t)}{d t}=\gamma(1-\sigma S(t))-(\mu+\alpha) Q_{t}(t) \\
& \frac{d Q_{p}(t)}{d t}=\sigma \gamma S(t)-\mu Q_{p}(t) .
\end{aligned}
$$

\begin{tabular}{|c|c|}
\hline $\begin{array}{l}\text { Par. } \\
\& \\
\text { Var. }\end{array}$ & Description \\
\hline$P(t)$ & Potential smoker population at time $t$ \\
\hline$L(t)$ & Light smoker population at time t. \\
\hline$S(t)$ & Heavy smoker population at time t. \\
\hline$Q_{t}(t)$ & $\begin{array}{l}\text { Smoker population who temporarily quit } \\
\text { smoking at time t }\end{array}$ \\
\hline$Q_{p}(t)$ & $\begin{array}{l}\text { Smoker population who permanently quit } \\
\text { smoking at time } t\end{array}$ \\
\hline$\alpha$ & $\begin{array}{l}\text { The contact rate between smoker and } \\
\text { temporary quitters who revert back to } \\
\text { smoking. }\end{array}$ \\
\hline$\beta_{1}$ & $\begin{array}{l}\text { The contact rate between potential smokers } \\
\text { and light smokers. }\end{array}$ \\
\hline$\beta_{2}$ & $\begin{array}{l}\text { The contact rate between light smokers and } \\
\text { heavy smokers. }\end{array}$ \\
\hline$\gamma$ & The rate of quitting smoking. \\
\hline$\mu$ & $\begin{array}{l}\text { The rate of natural death of human } \\
\text { population. }\end{array}$ \\
\hline$\sigma$ & $\begin{array}{l}\text { The remaining fraction of smokers who } \\
\text { permanently quit smoking (at a rate } \gamma \text { ). }\end{array}$ \\
\hline
\end{tabular}

with variables and parameters of the system (1) in the following table.
Table 1. Variables and Parameters Description

To control the spread of smoking in the community, we apply the optimal control strategy to system (1). We will consider three control variables in the form antismoking campaign, nicotine gum, and treatment to reduce the attitude towads smoking. An anti-smoking campaign is given to $P$. A nicotine gum is given to $L$ and $Q_{t}$. Then, for a treatment is given to $S$. Futhermore, a new system will be obtained after the system (1) is given controls. As for in more detail, the steps of this research are:

1. Formulating the dynamics model of smoking that has been given three controls.

2. Defining the objective function based on Pontryagin maximum principle.

3. Determining the optimal input control in Step 1, with the following steps:

a. Forming a differential equation into a Hamiltonian function.

b. Minimizing the Hamiltonian function so that the optimal control functions are obtained.

c. Determining the form of the optimal Hamiltonian function.

d. Resolving state and co-state equations.

e. Substituting the solution in Step 4 into the optimal control function in Step 2.

4. Substituting the optimal input control into the system so that the optimal form of feedback is obtained.

5. Simulating the results of the dynamics model of smoking numerically with the Runge-Kutta $4^{\text {th }}$ method by using Matlab software. 
6. Interpreting the simulation results of the dynamics model of smoking that have been obtained.

\section{RESULTS AND DISCUSSION}

In this paper, the control function $u_{1}$ represents antismoking campaign. This control is given to potential smokers in the community. In the beginning, potential smokers start smoking when they are in contact with smokers. This can be prevented with anti-smoking campaign. An anti-smoking campaign will provide direction for potential smokers about the dangers of smoking. Thus, potential smokers have no desire to smoke. The control $u_{2}$ represents nicotine gum. This control is given to light smokers and smokers who temporarily quit smoking. Light smokers is smokers who have the frequency of smoking occasionally. Next, smokers who temporarily quit smoking is individuals who quit smoking but still have a desire to smoke. A nicotine gum can prevent them from getting addicted and can treat these addictions gradually.

The control function $u_{3}$ represents treatment control. This control is given to heavy smokers because heavy smokers are more difficult to cure their addicted. Therefore, treatment control is expected to provide effective treatment. Heavy smokers is smokers who have the frequency of smoking continuously. Giving drugs is assumed that heavy smokers can reduce their smoking frequency from heavy smokers to light smokers and stop permanently, so that they become smokers who quit smoking permanently. The control that is carried out forms the dynamics model of smoking with control, namely:

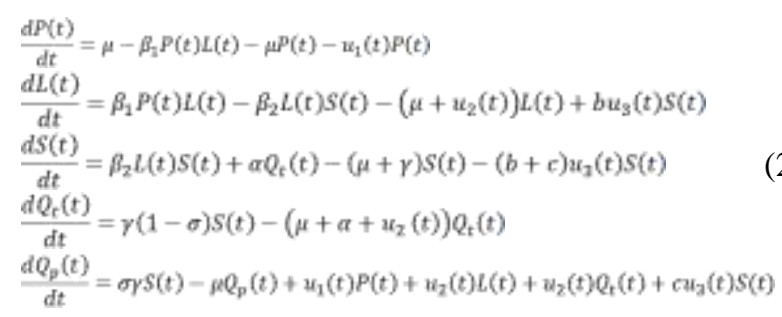

The purpose of this study is to minimize the number of populations from potential smokers, light smokers, heavy smokers, smokers who quit smoking temporarily and to minimize the cost of anti-smoking campaign, the cost of nicotine gum, and the cost of treatment. The another aim is to maximize the number of smokers who quit smoking permanently.

The relationship between the cost of the control variables $\left(u_{i}(t)\right)$ and the number of population has a non-linier relationship. This causes the cost function to be formed into a nonlinear model and quadratic function. $(u(v))^{2}$.

Based on the previous description, the cost function can be formulated $r_{1} u_{1}^{2}(t), r_{2} u_{2}^{2}(t)$ and $r_{3} u_{3}^{2}(t)$ where $r_{1}, r_{2}, r_{3}$ are the cost weights for the control variables. The objective functions is obtained as follows:

$I=\int_{0}^{t_{f}}\left[A_{1} S(t)-A_{2} Q_{p}(t)+\frac{1}{2}\left[r_{1} u_{1}^{2}(t)+r_{2} u_{2}^{2}(t)+r_{3} u_{3}^{2}(t)\right]\right] d t+A_{3} P\left(t_{f}\right)+A_{4} L\left(t_{f}\right)+A_{S} Q_{t}\left(t_{f}\right)$.

Here, a coefficient $A_{i}$ is weight factor (positive constant) that represents a smoker level of acceptance of the three controls. Next, $r_{1}$ is weight factor (positive constant) that correlates with the cost of the antismoking campaign. Whereas, $r_{2}$ and $r_{3}$ are weight factors (positive constants) that correlates with the cost of nicotine gum and the cost of treatment. Furthermore, the optimal control will be determined $u_{1}^{*}(t), u_{2}^{*}(t), u_{3}^{*}(t)$ as follows:

$f\left[u_{1}^{*}(t), u_{2}^{*}(t), u_{3}^{*}(t)\right]=\min \left\{f\left(u_{1}(t), u_{2}(t), u_{3}(t)\right) \mid u_{1}, u_{2}, u_{3} \in U\right\}$, where

$U=$
$\left\{\left(u_{1}, u_{2}\right) \mid 0 \leq u_{1}(t) \leq 0.9,0 \leq u_{2}(t) \leq 1,0 \leq u_{3}(t) \leq 1\right\}$.

Optimal control problem is solved by fulfilling the condition on Pontryagin's maximum principle.
The Hamiltonian that corresponds to the equation system is

$$
\begin{aligned}
& H(x, u, t, \lambda)=f(x, t, u)+\sum_{m=1}^{n} \lambda_{m}(t) g_{m}(x, t, u)
\end{aligned}
$$

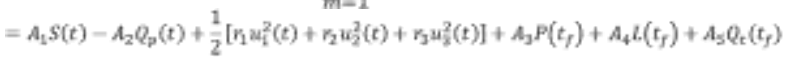

$$
\begin{aligned}
& +\lambda_{1}\left(\mu-\beta_{2} P(t) L(t)-\alpha_{1} P(t)-z_{1}(t) P(t)\right) \\
& +\lambda_{2}\left(\beta_{1} P(t) L(t)-\beta_{2} L(t) S(t)-\left(\mu+u_{2}(t)\right) L(t)+b_{2}\{t(t) S(t))\right. \\
& +h_{1}\left(\beta_{2} L(t) S(t)+a Q_{t}(t)-(\beta+y) S(t)-(b+e) \omega_{2}(t) S(t)\right) \\
& +\lambda_{4}\left(r(1-\sigma) S(t)-\left(\mu+\alpha+u_{3}(t)\right) Q_{t}(t)\right) \\
& +\lambda_{5}\left(\sigma r s(t)-\mu Q_{\varphi}(t)+u_{1}(t) P(t)+u_{2}(t) L(t)+u_{2}(t) Q_{1}(t)+c u_{2}(t) S(t)\right)
\end{aligned}
$$

To obtain the optimal condition, it must satisfy the stationary conditions of the Hamiltonian or $I I(x, u, t, \lambda)$ by solving the state system and the co-state system. The stationary conditions are conditions where optimal control $\left(u_{1}(t), u_{2}(t), u_{3}(t)\right)$ must be able to minimize the Hamiltonian at time $t$. The following are stationary conditions that can satisfy optimal conditions:

$r_{1} x_{1}(t)+\left(\lambda_{j}-\lambda_{1}\right) P(t)-0$ 


$$
\begin{aligned}
& r_{2} u_{2}(t)+\left(\lambda_{5}-\lambda_{2}\right) L(t)+\left(\lambda_{5}-\lambda_{4}\right) Q_{t}(t)=0 \\
& r_{3} u_{3}(t)+\left(\lambda_{2}-\lambda_{3}\right) b S(t)+\left(\lambda_{5}-\lambda_{3}\right) c S(t)=0
\end{aligned}
$$

The optimal control function can be written as

$$
\begin{aligned}
& u_{1}^{5}(t)=\frac{\left(\lambda_{1}-\lambda_{s}\right) P(t)}{r_{1}} \\
& u_{2}^{*}(t)=\frac{\left(\lambda_{2}-\lambda_{5}\right) I_{c}(t)+\left(\lambda_{4}-\lambda_{5}\right) Q_{i}(t)}{r_{2}} \\
& u_{3}^{*}(t)=\frac{\left[\left(\lambda_{3}-\lambda_{2}\right) b+\left(\lambda_{3}-\lambda_{5}\right) c\right] S(t)}{r_{3}}
\end{aligned}
$$

The control variables satisfy $u_{1}(t) \subset[0,0.9]$, $u_{2}(t) \in[0,1]$, dan $u_{3}(t) \subset[0,1]$, so it will obtained several possible results are as follows:

$u_{1}^{*}(t)=\left\{\begin{array}{ll}v_{0}, & \text { If } 0<v<0.9 \\ 0, & \text { If } v<0 \\ 0.9, & \text { if } v \geqslant 0.9\end{array} \quad\right.$ with $\quad v=\frac{\left(\lambda_{1}-\lambda_{s}\right) P(t)}{r_{1}}$

and

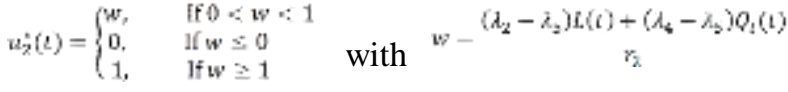

also

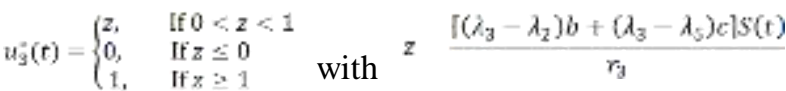

Thus, the optimal control values $u_{1}^{*}, u_{2}^{*}, u_{3}^{*}$ can be stated as follows:

$$
\begin{aligned}
& u_{1}^{*}(t)=\min \left\{\max \left\{0, \frac{\left(\lambda_{1}-\lambda_{5}\right) P(t)}{r_{1}}\right\}, u_{1 \max }\right\} \\
& u_{2}^{*}(t)=\min \left\{\max \left\{0, \frac{\left(\lambda_{2}-\lambda_{5}\right) L(t)+\left(\lambda_{4}-\lambda_{5}\right) Q_{t}(t)}{r_{2}}\right\}, u_{2 \max }\right\} \\
& u_{3}^{*}(t)=\min \left\{\max \left\{0, \frac{\left[\left(\lambda_{3}-\lambda_{2}\right) b+\left(\lambda_{3}-\lambda_{5}\right) c\right] S(t)}{r_{3}}\right\}, u_{3 \max }\right\}
\end{aligned}
$$

The next process is to determine the optimal form of Hamiltonian by substituting $u_{i}^{*}$ into the form Hamiltonian. Here, $u_{i}^{*}$ is obtained in Step 2.

$$
\begin{aligned}
H^{*}\left(x^{*}(t), u^{*}(t), \lambda^{*}(t), t\right) & =A_{1} S(t)-\lambda_{2} Q_{p}(t)+\frac{1}{2} r_{1}\left(\frac{\left(\lambda_{1}^{*}-\lambda_{5}^{*}\right) P^{*}(t)}{r_{1}}\right)^{2} \\
& +\frac{1}{2} r_{2}\left(\frac{\left(\lambda_{2}^{*}-\lambda_{5}^{*}\right) L(t)+\left(\lambda_{4}^{*}-\lambda_{5}^{*}\right) Q_{t}^{*}(t)}{r_{2}}\right)^{2}+\frac{1}{2} r_{3}\left(\frac{\left[\left(\lambda_{3}^{*}-\lambda_{2}^{*}\right) b+\left(\lambda_{3}^{*}-\lambda_{5}^{*}\right) c\right] S^{*}(t)}{r_{3}}\right)^{2} \\
& +A_{3} P^{*}\left(t_{f}\right)+A_{4} L^{*}\left(t_{f}\right)+A_{5} Q_{t}^{*}\left(t_{f}\right)+\lambda_{1}^{*} \mu-\lambda_{1}^{*} \beta_{1} P^{*}(t) L^{*}(t)-\lambda_{1}^{*} \mu P^{*}(t) \\
& -\left(\frac{\left(\lambda_{1}^{*}-\lambda_{5}^{*}\right) P^{*}(t)}{r_{1}}\right) P^{*}(t)+\lambda_{2}^{*} \beta_{1} P^{*}(t) L^{*}(t)-\lambda_{2}^{*} \beta_{2} L^{*}(t) S^{*}(t)-\lambda_{2}^{*}\left(\mu+u_{2}(t)\right) L^{*}(t) \\
& +\lambda_{2}^{*} b\left(\frac{\left[\left(\lambda_{3}^{*}-\lambda_{2}^{*}\right) b+\left(\lambda_{3}^{*}-\lambda_{5}^{*}\right) c\right] S^{*}(t)}{r_{3}}\right) S^{*}(t)+\lambda_{3}^{*} \beta_{2} L^{*}(t) S^{*}(t) \\
& +\lambda_{4}^{*}\left(\gamma(1-\sigma) S^{*}(t)\right)-\lambda_{4}^{*}\left(\mu+\alpha+\frac{\left(\lambda_{2}^{*}-\lambda_{5}^{*}\right) L(t)+\left(\lambda_{4}^{*}-\lambda_{5}^{*}\right) Q_{t}^{*}(t)}{r_{2}}\right) Q_{t}^{*}(t) \\
& +\lambda_{5}^{*} \sigma \gamma S(t)-\lambda_{5}^{*} \mu Q_{p}(t)+\lambda_{5}^{*}\left(\frac{\left(\lambda_{1}^{*}-\lambda_{5}^{*}\right) P^{*}(t)}{r_{1}}\right) P^{*}(t) \\
& +\lambda_{5}^{*}\left(\frac{\left(\lambda_{2}^{*}-\lambda_{5}^{*}\right) L(t)+\left(\lambda_{4}^{*}-\lambda_{5}^{*}\right) Q_{t}^{*}(t)}{r_{2}}\right) L^{*}(t) \\
& +\lambda_{5}^{*}\left(\frac{\left(\lambda_{2}^{*}-\lambda_{5}^{*}\right) L(t)+\left(\lambda_{4}^{*}-\lambda_{5}^{*}\right) Q_{t}^{*}(t)}{r_{2}}\right) Q_{t}^{*}(t) \\
& +\lambda_{5}^{*} c\left(\frac{\left[\left(\lambda_{j}^{*}-\lambda_{2}^{*}\right) b+\left(\lambda_{3}^{*}-\lambda_{5}^{*}\right) c\right] S^{*}(t)}{r_{3}}\right) S^{*}(t)
\end{aligned}
$$

Then the state system will be solved. This system is equation system that becomes an obstacle in solving the optimal control problem. Based on the equation system (2) the state system is obtained as follows:

$$
\begin{aligned}
& \frac{d P(t)}{d t}=\frac{\partial H}{\partial \lambda_{1}}=\mu-\beta_{1} P(t) L(t)-\mu P(t)-u_{1}(t) P(t) \\
& \frac{d L(t)}{d t}=\frac{\partial H}{\partial \lambda_{2}}=\beta_{1} P(t) L(t)-\beta_{2} L(t) S(t)-\left(\mu+u_{2}(t)\right) L(t)+b u_{3}(t) S(t) \\
& \frac{d S(t)}{d t}=\frac{\partial H}{\partial \lambda_{3}}=\beta_{2} L(t) S(t)+\alpha Q_{t}(t)-(\mu+\gamma) S(t)-(b+c) u_{3}(t) S(t) \\
& \frac{d Q_{t}(t)}{d t}=\frac{\partial H}{\partial \lambda_{4}}=\gamma(1-\sigma) S(t)-\left(\mu+\alpha+u_{2}(t)\right) Q_{t}(t) \\
& \frac{d Q_{p}(t)}{d t}=\frac{\partial H}{\partial \lambda_{5}}=\sigma \gamma S(t)-\mu Q_{p}(t)+u_{1}(t) P(t)+u_{2}(t) L(t)+u_{2}(t) Q_{t}(t)+c u_{3}(t) S(t)
\end{aligned}
$$


where initial condition

$P(0)-P_{0}, L(0)-L_{0}, S(0)-S_{0}, Q_{4}(0)-L_{0}$, and

$Q_{p}(0)=Q_{p_{0}}$
To find co-state variables or adjoint variables $\left(\lambda_{1}, \lambda_{2}, \lambda_{3}, \lambda_{4}, \lambda_{3}\right)$ in the control form $u^{*}$. We solve the co-state equations, then we get the co-state variables. Co-state equations is a negative value of the Hamiltonian function that derived from state variables or

$$
\begin{aligned}
& \frac{d \lambda_{1}}{d t}=-\frac{\partial H}{\partial P}=-A_{3}+\lambda_{1}\left(\beta_{1} L(t)+\mu+u_{1}(t)\right)-\lambda_{2} \beta_{1} L(t)-\lambda_{5} u_{1}(t) \\
& \frac{d \lambda_{2}}{d t}=-\frac{\partial H}{\partial L}=-A_{4}+\lambda_{1}\left(\beta_{1} P(t)\right)-\lambda_{2}\left(\beta_{1} P(t)-\beta_{2} S(t)-\left(\mu+u_{2}\right)\right)-\lambda_{3} \beta_{2} S(t)-\lambda_{5} u_{2}(t) \\
& \frac{d \lambda_{3}}{d t}=-\frac{\partial H}{\partial S}=-A_{1}+\lambda_{2}\left(\beta_{2} L(t)-b u_{3}(t)\right)-\lambda_{3}\left(\beta_{2} L(t)-(\mu+\gamma)-(b+c) u_{3}(t)\right)-\lambda_{4}(\gamma(1-\sigma)) \\
& -\lambda_{5}\left(\sigma \gamma+c u_{3}(t)\right) \\
& \frac{d \lambda_{4}}{d t}=-\frac{\partial H}{\partial Q_{t}}=-A_{S}-\lambda_{3} \alpha+\lambda_{4}\left(\left(\mu+\alpha+u_{2}(t)\right)-\lambda_{5} u_{2}(t)\right. \\
& \frac{d \lambda_{s}}{d t}=-\frac{\partial H}{\partial Q_{p}}=A_{2}+\lambda_{5} \mu
\end{aligned}
$$

with transversal condition is

$\lambda_{1}\left(t_{f}\right)=\lambda_{2}\left(t_{f}\right)=\lambda_{3}\left(t_{f}\right)=\lambda_{4}\left(t_{f}\right)=\lambda_{5}\left(t_{f}\right)=$
The solution for the optimal system will be obtained by substituting the value of the control optimal $u_{i}^{*}$ into the system of state equations (4) and the system of costate equations (5), so that the optimal solution form is as follows:

$$
\begin{aligned}
& \frac{\partial H}{\partial \lambda_{1}^{*}}=\frac{d P^{*}(t)}{d t}=\mu-\beta_{1} P^{*}(t) L^{t}(t)-\mu P^{*}(t)-u_{1}^{*}(t) P^{*}(t) . \\
& \frac{\partial H}{\partial \lambda_{2}^{*}}=\frac{d L^{*}(t)}{d t}=\beta_{1} P^{*}(t) L^{*}(t)-\beta_{2} L^{*}(t) S^{*}(t)-\left(\mu+u_{2}^{*}(t)\right) L^{*}(t)+b u_{3}^{*}(t) S^{*}(t) . \\
& \frac{\partial H}{\partial \lambda_{3}^{*}}=\frac{d S^{*}(t)}{d t}=\beta_{2} E^{*}(t) S^{*}(t)+a Q_{f}^{*}(t)-(p+\gamma) S^{*}(t)-(b+c) u_{3}^{*}(t) S^{*}(t) . \\
& \frac{\partial H}{\partial \lambda_{4}^{*}}=\frac{d Q_{t}^{*}(t)}{d t}=\gamma(1-\sigma) S^{*}(t)-\left(\mu+\alpha+u_{2}^{*}(t)\right) Q_{t}^{*}(t) \\
& \frac{\partial H}{\partial \lambda_{5}^{*}}=\frac{d Q_{p}^{*}(t)}{d t}=\sigma \gamma S^{*}(t)-\mu Q_{p}^{*}(t)+u_{1}^{*}(t) P^{*}(t)+u_{2}^{*}(t) L^{*}(t)+u_{z}^{*}(t) Q_{t}^{*}(t)+c u_{3}^{*}(t) S^{*}(t) \\
& \frac{d \lambda_{1}^{*}}{d t}=-\frac{\partial H}{\partial P^{*}}=-A_{3}+\lambda_{1}\left(\beta_{1} L^{*}(t)+\mu+u_{1}^{*}(t)\right)-\lambda_{2} \beta_{1} L^{*}(t)-\lambda_{5} u_{1}^{*}(t) \\
& \frac{d \lambda_{2}^{*}}{d t}=-\frac{\partial H}{\partial L^{*}}=-A_{4}+\lambda_{1}\left(\beta_{1} P^{*}(t)\right)-\lambda_{2}\left(\beta_{1} P^{*}(t)-\beta_{2} S^{*}(t)-\left(\mu+u_{2}^{*}\right)\right)-\lambda_{3} \beta_{2} S^{*}(t)-\lambda_{5} u_{2}^{*}(t) \\
& \frac{d \lambda_{3}^{*}}{d t}=-\frac{\partial H}{\partial S^{*}}=-A_{1}+\lambda_{2}\left(\beta_{2} L^{*}(t)-b u_{3}^{*}(t)\right)-\lambda_{3}\left(\beta_{2} L^{*}(t)-(\mu+\gamma)-(b+c) u_{3}^{*}(t)\right) \\
& -\lambda_{4}(\gamma(1-\sigma))-\lambda_{5}\left(\sigma \gamma+c u_{3}^{*}(t)\right) \\
& \frac{d \lambda_{4}^{*}}{d t}=-\frac{\partial H}{\partial Q_{t}^{*}}=-A_{5}-\lambda_{3} \alpha+\lambda_{4}\left(\left(\mu+\alpha+u_{2}^{*}(t)\right)-\lambda_{5} u_{2}^{*}(t)\right. \\
& \frac{d \lambda_{5}^{*}}{d t}=-\frac{\partial H}{\partial Q_{p}^{*}}=A_{2}+\lambda_{5} \mu
\end{aligned}
$$

with boundary conditions such as $P(0)=P_{0}, L(0)=L_{0}, S(0)=S_{0}, Q_{t}(0)=Q_{t_{0}} \quad$ and $\quad$ also $\quad \lambda_{1}\left(t_{f}\right)=\lambda_{2}\left(t_{f}\right)=\lambda_{3}\left(t_{f}\right)=\lambda_{4}\left(t_{f}\right)=$ $Q_{t}(0)=Q_{t_{\mathrm{a}}}$. $0, \lambda_{5}\left(t_{f}\right)=0$ 
Simulation of optimal control problem will be solved using the forward and backward sweep algorithm. The algorithm is applied to MATLAB by defining it on the M-File with parameters. Previously, these parameters have been given. In this simulation, the dynamics model of smoking with three controls has variables, namely: $P, L, S, Q_{t}, Q_{p}, \lambda_{1}, \lambda_{2}, \lambda_{3}, \lambda_{4}$, and also $\lambda_{5}, u_{1}, u_{2}, u_{3}$ which are stated in notation or symbol the following,

$P(i), L(i), S(i), Q_{t}(i), Q_{p}(i), \lambda_{1}(i), \lambda_{2}(i), \lambda_{3}(i), \lambda_{4}(i), \lambda_{5}(i), u_{1}(i), u_{2}(i)$, and $u_{3}(i)$ with $i=0,1,2, \ldots$. The steps of the forward and backward sweep algorithm are as following [10],

1. Determining the initial values:

$P(0), L(0), S(0), Q_{t}(0), Q_{p}(0), \lambda_{1}(n)=$

$\lambda_{2}(n)=0$

and $\lambda_{3}(n)-\lambda_{4}(n)-\lambda_{5}(n)-0 \quad$ and also error tolerance. In first step, it will be given initial values of parameters of the dynamics model of smoking as follows: $P(0), L(0), S(0), Q_{t}(0), Q_{p}(0)$. Besides that, we also determine the size of the step $(h=0.1)$.

Table 2. Initial Value for Numeric Simulation

\begin{tabular}{|l|l|l|l|l|}
\hline$P(0)$ & $L(0)$ & $S(0)$ & $Q_{t}(0)$ & $Q_{p}(0)$ \\
\hline 0.60301 & 0.24 & 0.10628 & 0.03260 & 0.01811 \\
\hline
\end{tabular}

2. Making initial guesses $u_{1}, u_{2}$ and $u_{3}$.

3. Calculating value $P(i+1), L(i+1), S(i+1), Q_{t}(i+1), Q_{p}(i+$

1)

with initial values in Step 1. This calculation uses the Runge-Kutta method of order 4 with forward step.

4. Calculating value

$\lambda_{1}(p-1), \lambda_{2}(p-1), \lambda_{3}(p-1), \lambda_{4}(p-$

1), $\lambda_{5}(p-1)$

from

with transversal conditions. This calculation uses the Runge-Kutta method of order 4 with backward step.

5. Calculating the value of the control variables.

$$
\begin{aligned}
& \left.u_{1}(n)=\min \left\{\max \left\{0, \frac{\left(\lambda_{1}(n)-\lambda_{3}(n)\right) P(n)}{r_{1}}\right\}, u_{1}\right)\right\} \\
& u_{2}(n)=\min \left\{\max \left\{0, \frac{\left(\lambda_{2}(n)-\lambda_{5}(n)\right) L(n)+\left(\lambda_{4}(n)-\lambda_{5}(n)\right) Q_{6}(n)}{r_{2}}\right\}, u_{2 \max }\right\} \\
& u_{3}(n)=\min \left\{\max \left\{0, \frac{\left[\left(\lambda_{3}(n)-\lambda_{2}(n)\right) b+\left(\lambda_{3}(n)-\lambda_{5}(n)\right) c\right] S(n)}{r_{3}}\right\}, u_{3 \max }\right\}
\end{aligned}
$$

6. Calculating error values for variables, namely $P, L, S, Q_{t}, Q_{p}, \lambda_{1}, \lambda_{2}, \lambda_{3}, \lambda_{4}, \lambda_{5}, u_{1}, u_{2}$ and $u_{3}$ based on current and previous iteration values. If the error value is greater than tolerance then return to Step 3.
7. Print

$$
\begin{aligned}
& P^{*}=P, L^{*}=L, S^{*}=S, Q_{t}^{*}=Q_{t}, Q_{p}^{*}= \\
& Q_{p}, u_{1}^{*}=u_{1}, u_{2}^{*}=u_{2} \\
& \text { and } u_{3}^{*}=u_{3} .
\end{aligned}
$$

\section{NUMERICAL RESULTS}

This simulation process is useful to look the total population of potential smokers, light smokers, heavy smokers, smokers who quit smoking temporarily and smokers who quit smoking permanently so the simulation results 2 (two) graphs. First, the graphs show the dynamic model of smoking without controls. Then, the graphs after these three controls are given. The parameter value used is:

Table 3. Variables and Parameters Value

\begin{tabular}{|l|l|l|l|l|l|}
\hline $\begin{array}{l}\text { Par } \\
\alpha\end{array}$ & Value & $\begin{array}{l}\text { Referenc } \\
\text { es }\end{array}$ & $\begin{array}{l}\text { Par } \\
\cdot\end{array}$ & Value & Reference \\
\hline$\beta_{1}$ & 0.23 & {$[1]$} & $A_{1}$ & 0.3 & $\begin{array}{l}\text { Assump- } \\
\text { tion }\end{array}$ \\
\hline$\beta_{2}$ & 0.3 & {$[1]$} & $A_{3}$ & 0.1 & $\begin{array}{l}\text { Assump- } \\
\text { tion }\end{array}$ \\
\hline$\mu$ & 0.04 & {$[1]$} & $A_{4}$ & 0.3 & $\begin{array}{l}\text { Assump- } \\
\text { tion }\end{array}$ \\
\hline$\sigma$ & 0.4 & {$[1]$} & $A_{5}$ & 0.1 & $\begin{array}{l}\text { Assump- } \\
\text { tion }\end{array}$ \\
\hline$\gamma$ & 0.2 & {$[1]$} & $r_{1}$ & 0.2 & $\begin{array}{l}\text { Assump- } \\
\text { tion }\end{array}$ \\
\hline$b$ & 0.25 & $\begin{array}{l}\text { Assump- } \\
\text { tion }\end{array}$ & $r_{2}$ & 0.3 & $\begin{array}{l}\text { Assump- } \\
\text { tion }\end{array}$ \\
\hline$c$ & 0.5 & $\begin{array}{l}\text { Assump- } \\
\text { tion }\end{array}$ & $r_{3}$ & 0.5 & $\begin{array}{l}\text { Assump- } \\
\text { tion }\end{array}$ \\
\hline
\end{tabular}

Figure $2-5$ show the population solution model of smoking without controls and with controls.

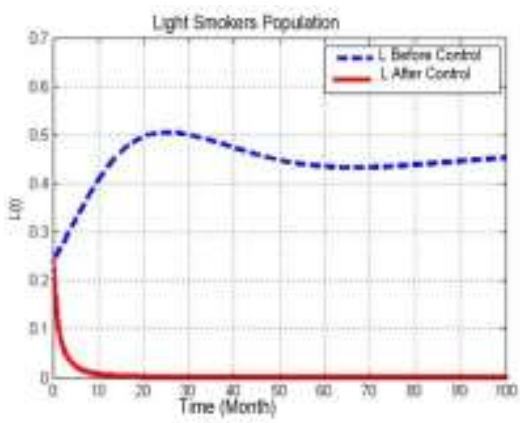

Figure 2 Numerical Solution of Light Smoker population 
Figure 2 illustrates condition before (blue line) and after (red line) control included in the simulation. A significant increase show up in the light smoker population until the $25^{\text {th }}$ month and then began to experience decline. The light smoker population reach the lowest point in the $64^{\text {th }}$ month and increased slowly until $100^{\text {th }}$ month. Then the population moves constant towards the equilibrium point so that the lighter smoker will always exist indefinitely. Therefore, light smokers are endemic and will not disappear from the population if there are no control in the population. This is different when control treatment as nicotine gum is given to the light population which show us that the light population has decreased continuously. If on the graph without control in the $25^{\text {th }}$ month, the population is 0.5051 then after given control, population of light smokers in the 25 th month is 0.001414 .

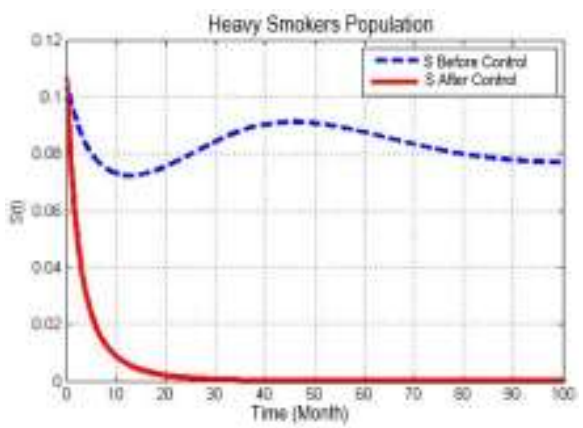

Figure 3 Numerical Solution of Heavy Smoker population

Figure 3 is a numerical simulation showing the dynamic of heavy smokers population before (blue dash) and after control (red line). Population heavy smokers before control decrease at the $12^{\text {th }}$ month, then go to maximum increases at the $45^{\text {th }}$ month. This population decline until $100^{\text {th }}$ month. This population goes to the endemic equilibria when heavy smoker population will be exist in the environment before control. The red line plot shows a significant decrease from heavy smokers population, from the $1^{\text {st }}$ month until $48^{\text {th }}$ month and then the population goes to zero. This decrease occurred as a result of giving treatment for the heavy smoker as control so it will increase the number of quitter smoker.

Figure 4 shows a simulation of a temporary nonsmoker population before (blue dash) and after control (red line). The control given using a nicotine gum as a treatment for heavy smoker. The temporary non-smoker population before control increases in the $3^{\text {rd }}$ month then decreased in the $16^{\text {th }}$ month. After that, the population increased significantly until the $48^{\text {th }}$ month. This increase in population occurs due to population of heavy smokers who stop smoking temporarily so that they become temporary non-smoker. Meanwhile, the decrease was due to temporary non-smokers who returned to being heavy smokers. Nicotine chewing gum as a control treatment is give a significant effect to decrease the number of temporary quitter population. This population has decreased due to temporary nonsmokers has become a permanent non-smoker.

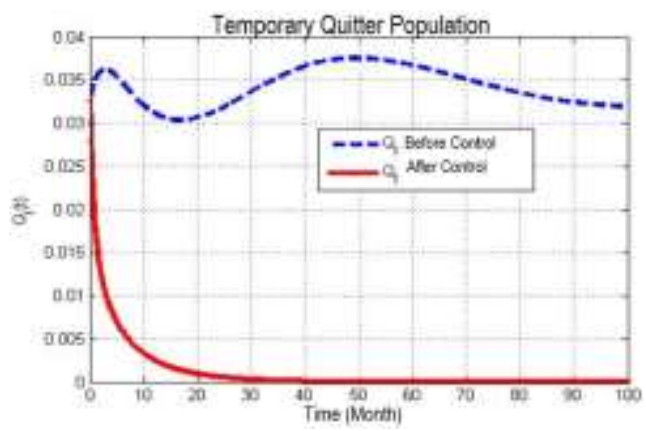

Figure 4 Numerical Solution of Temporary Quitter Population

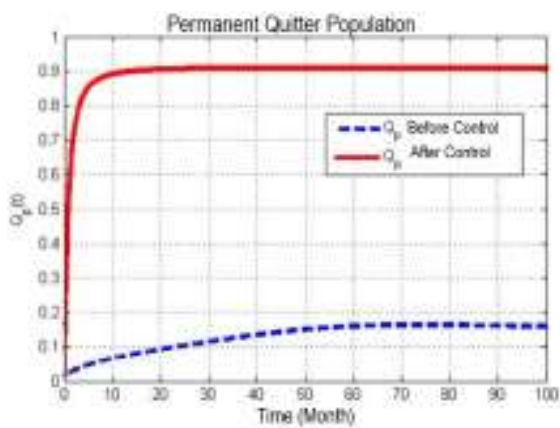

Figure 5 Numerical Solution of Permanent Quitter Population

Figure 5 is a simulation result for population of permanent quitter smokers before (blue dash) and after control (red line). The red line is the population after control which shows that non-permanent smokers have increased up to months the $66^{\text {th }}$ and so on until the $100^{\text {th }}$ month. This is due to the presence of heavy and light smoker person who quit smoking. Meanwhile, after being given 3 controls, the rate of the increase in the population of permanent non-smokers is very fast. This is due to the presence of smokers weight to quit smoking. Meanwhile, after being given 3 controls, the rate of the increase in the population of permanent nonsmokers is very fast.

\section{CONCLUSION}

Based on the description of the previous discussion, the conclusion is the dynamics model of smoking with five populations can be modified by providing three controls. These three controls consists of anti-smoking campaign, nicotine gum, and treatment. The first control is given to potential smokers. The second control is given to light smokers and smokers who quit smoking temporarily and the last control is given to heavy smokers. These three controls aim to minimize the number of potential smokers, light smokers, heavy smokers and smokers who quit smoking permanently 
and also to minimize the cost of anti-smoking campaign, the cost of nicotine gum, and the cost of treatment. Besides that, to maximize the number of smoker who quit permanently. The results of numerical simulations show effectiveness control after being given three controls. The results can maximize and minimize the population.

In future research, studies on the dynamics of the smoking population by age structure can be developed. Thus, the number of adolescent and child smokers can be reduced effectively and significantly.

\section{REFERENCES}

[1] Z. Alkhudari, S. Al-Sheikh, S. Al-Tuwairqi, The effect of ocassional smokers on the dynamics of a smoking model, in: International Mathematical Forum, vol. 9, 2014, pp. 1207-1222.

[2] O. Chaturvedi, P. Chaturvedi, Nicotine gum in smoking cessation, in: International Journal of Contemporary Medical Research, vol. 9, 2017, pp. 1964-1966.

[3] N. Fawzani, A. Triratnawati, Terapi berhenti merokok (studi kasus 3 perokok berat), in: Makara, Kesehatan, vol. 9, 2005, pp. 15-22.

[4] Fuadah, M. Gambaran faktor-faktor yang mempengaruhi perilaku merokok pada mahasiswa laki-laki Fakultas Teknik Universitas Negeri
Jakarta Angkatan 2009 (Skripsi S1). Depok: Universitas Indonesia. 2011.

[5] R. Govan, J. Puspita, Membangun model penyebaran perilaku merokok berdasarkan faktor biologis dan faktor lingkungan sosial, in: Jurnal Ilmiah Matematika Terapan, vol. 13, 2016, pp. 3547.

[6] Suharjana, Kebiasaan berperilaku hidup sehat dan nilai-nilai pendidikan karakter, in: Jurnal Pendidikan Karakter, vol. 2(2), 2012, pp. 189-201.

[7] World Health Organization, WHO report on the global tobacco epidemic, the Mpower package, WHO, Geneva, 2008.

[8] G. Zaman, Optimal campaign in the smoking dynamics, in: Computational and Mathematical Methods in Medicine, 2011, pp. 1-9.

[9] A. Zeb, F. Bibi, G. Zaman, Optimal control strategies in square root dynamics of smoking model, in: International Journal of Scientific World, vol. 3, 2015, pp. 91-97.

[10] Zulaikha, Trisilowati, I. Fadhillah, Kontrol optimal pada model epidemi SEIQR dengan tingkat kejadian standar, in: Prosiding SI MaNIs, vol. 1(1), 2017, pp. 41-51. 